\title{
FERNANDO PESSOA: LEITOR DE CARLYLE
}

Alex Neiva ${ }^{1}$

\begin{abstract}
RESUMO: Este artigo abordará as leituras que Fernando Pessoa realizou do historiador e ensaísta escocês Thomas Carlyle (1795 - 1881). A pesquisa tem por objetivo estudar as origens do pensamento carlyleano em Pessoa, a partir da identificação de conceitos históricos e políticos que tenham sido formulados por Carlyle e retomados pelo poeta. Parte-se da constatação de que a noção pessoana de "gênio" assenta sobre o terreno fértil do pensamento carlyleano. No centro das contribuições de Carlyle para o pensamento pessoano está a supressão de fronteiras tanto temporais quanto espaciais como forma de compreender a representação do sentimento nacional. Exemplos desse modo de pensar são recorrentes na obra do escritor escocês. Tenciona-se evidenciar possíveis pontos de confluência entre as obras, a fim de ressaltar o importante papel que essa leitura teve para a construção da noção de gênio em Pessoa.
\end{abstract}

PALAVRAS-CHAVE: Fernando Pessoa, Thomas Carlyle, Gênio, Herói.

\section{FERNANDO PESSOA: CARLYLE'S READER}

ABSTRACT: This paper will discuss Fernando Pessoa's reading about the Scottish historian and essayist Thomas Carlyle (1795-1881). The research aims to study the origins of carlylean's thinking in Pessoa from the identification of historical and political factors that have been formulated by Carlyle and taken over by poet concepts. Pessoa's notion of "genius" is based on the fertile ground of carlylean's thought. In the center of the contributions of Carlyle for Pessoa's thought is the suppression of both temporal and spatial boundaries as a way of understanding the representation of national sentiment. Examples of this way of thinking are recurrent in the work of the Scottish writer. It is intended to highlight possible points of confluence between the works in order to highlight the important role that reading had to build the notion of genius in Pessoa.

KEYWORDS: Fernando Pessoa, Thomas Carlyle, Genius, Heroes.

Estes homens, afinal, obtiveram tudo quanto a mão pode atingir, estendendo o braço. Variava neles o cumprimento do braço; no resto eram iguais. Não consegui nunca ter inveja desta espécie de gente. Achei sempre que a virtude estava em obter o que se não alcançava, em viver onde se não está, em ser mais vivo depois de morto que quando se está vivo - em conseguir, enfim, qualquer coisa de difícil, de absurdo, em vencer, como obstáculo, a própria realidade do mundo.

Pessoa, Livro do Desassossego, Trecho 145

\footnotetext{
${ }^{1}$ Mestrando do Programa de Pós-Graduação em Literatura Portuguesa da Universidade de São Paulo. Bolsista FAPESP.
} 
Honremos o grande império do silêncio, mais uma vez. Tesouro infinito esse, que não faz barulho nas nossas algibeiras, que não contamos por peça, que não exibimos diante dos homens! É talvez, de todas as coisas, a mais útil para cada um de nós, nestes tempos barulhentos.

Carlyle, Os Heróis, p.98

O primeiro contato de Pessoa com a obra de Carlyle se deu muito cedo, por volta de 1904, aos 16 anos, em Durban, África do Sul. Pessoa cursou a Form VI no colégio de Durban, nível equivalente ao primeiro ano de universidade. Carlyle constava no programa para a prova de ingresso ao Durban High School, exame que era administrado pela Universidade do Cabo da Boa Esperança (SEVERINO, 1983, p.72). Ainda nesse mesmo ano, na revista do liceu, intitulada The Durban High School, Pessoa publica o seu primeiro texto crítico, um ensaio sobre Thomas Babington Macaulay, autor inglês que escreveu History of England. Uma das características marcantes deste ensaio, segundo Fernando Cabral Martins, se deve ao fato de Pessoa contrapor ostensivamente Macaulay a Carlyle com a notória preferência do poeta pelo historiador escocês, a quem Pessoa considera, de maneira entusiasmada, um gênio (MARTINS, 2010, p.423).

Conforme a relação de livros de Pessoa apresentados por Maria Encarnação Monteiro (1956, p.24), pode-se afirmar que duas obras de Carlyle foram adquiridas pelo poeta nesta época. Da relação de livros constam em um único volume Sartor Resartus, Heroes e Past and Present. Em outro volume, está o livro The French Revolution. Na obra, há as seguintes anotações: “Ass.F.A.N.Pessôa, February, 1904.” Com a indicação: Durban High School, Form VI. Muitos sublinhados e observações sobre o estilo de Carlyle e sobre o gênio. Segundo Alexandrino E. Severino (1983, p.84), dois meses após esse último apontamento, Pessoa adquire um trabalho sobre Carlyle escrito por John Nichol para a coleção "English Men of Letters". A obra é assinada: “Ass. F.A.N.Pessôa, April, 1904”. Nas notas reunidas por Côrtes-Rodrigues, escritas pelo próprio Pessoa em 1914, consta Carlyle como uma das influências recebidas neste ano de 1904 (MONTEIRO, 1956, p.129).

Atualmente, encontram-se na biblioteca particular de Pessoa, com anotações e apontamentos feitos pelo próprio poeta, os livros: The French Revolution: a history in three volumes (existe apenas o volume I: "The Bastile"), Sartor Resartus, On Heroes, Hero-Worship and the Heroic in History e Past and Present.

As similitudes temáticas entre os autores se evidenciam de modo especialmente sugestivo no único texto de ficção de Carlyle, Sartor Resartus. A obra se compõe a partir da alternância das vozes de dois personagens. A primeira é de um editor inglês de nome 
desconhecido. A segunda voz é a de um filósofo e professor alemão, Diogenes Teufelsdröckh, o qual publicou supostamente uma dissertação filosófica sobre as vestimentas. O editor faz uma resenha sobre o livro Clothes, their Origin and Influence. Tal análise baseia-se na crítica e interpretação de "Philosophy of clothes", de Diogenes. A respeito da "filosofia das roupas", Pessoa sublinhou no exemplar de seu livro algumas passagens como: "all objects are as Windows", "All visible things are Emblems" e "Whatever sensibly exists, whatsoever represents Spirit to Spirit, is properly a Clothing, a suit of Raiment, put on for a season, and to be laid off' (CARLYLE, 1903, livro I, cap. XI). Carlyle faz ainda menção a um grego de nome Heróstrato, o qual Pessoa adotou como título de um ensaio. Esta figura, até 356 a.C., era desconhecida em Éfeso, tendo se tornado célebre após atear fogo no templo grego de Diana com o propósito declarado de se tornar conhecido. Tanto Carlyle como Pessoa partilham do interesse por discutir a celebridade póstuma, notadamente aquela de cariz literário que perpetuaria o mito do gênio a partir da realização plena de uma obra em vida.

É inegável a contribuição de Carlyle para o desenvolvimento das reflexões sobre o tema, notadamente nos textos extraídos de conferências dedicadas aos heróis, nos quais Carlyle se interessa pelas personalidades que deixaram marcas indeléveis na História. Pessoa assim ressalta a vocação poética do escritor escocês: "Carlyle more a poet than a philosopher. His works betray all the characteristics of poetry: the incoherence of presentation, the abundance of sentiment, etc. All this is of course poetry; neither philosophy nor science" (PIZZARO, 2007, p.80). Pessoa, aliás, afirma sobre si mesmo que não é um filósofo com faculdades poéticas, mas sim "um poeta inspirado pela filosofia" (PESSOA, 1973, p.14).

Vem a propósito considerar a carta que Ernest A. Belcher, professor de inglês de Pessoa na Durban High School, escreve, em 1907, ao alter-ego pessoano Faustino Antunes. Neste texto, que consta na edição Escritos Autobiográficos, Automáticos e de Reflexão Pessoal, Belcher revela que Pessoa era um grande admirador de Carlyle e que tinha dificuldade para refrear a tendência do poeta para imitar o estilo do escritor escocês: "I had some difficulty in checking a disposition on his part to imitate very closely Carlyle's style" (PESSOA, 2003, p.390).

Ainda a respeito do romance de Carlyle, vale lembrar que o pesquisador Richard Zenith faz menção em uma nota de rodapé de uma comunicação sua, apresentada no III Colóquio Internacional Fernando Pessoa, a uma lista de tarefas escritas por Pessoa, datada de Setembro de 1907 (E3/133f-53v), na qual se lê: "Finish reading first part 'Sartor". Zenith ressalta ainda que "a julgar pela caligrafia, as notas marginais inscritas no livro serão quase todas de 1907, parecendo provável que Pessoa, em Durban, tenha lido principalmente a outra obra de Carlyle incluída no mesmo volume: Heroes; Past and Present" (ZENITH, 2013, p.6). 
Há muitos comentários e diversas passagens sublinhadas nas notas marginais do exemplar pessoano de Sartor Resartus, dentre os quais se destaca: “'Sartor Resartus' is useful in giving to us an analysis of genius, a sort of soul-autobiography. Psychologists should take notice of it". Segundo Zenith (2013, p.7), que identifica Sartor Resartus como um dos precursores do Livro do Desassossego, Pessoa, em 1907, chegou, inclusive, a pensar em escrever uma espécie de Sartor Resartus:

Segundo um apontamento patente num caderno usado por Pessoa nesse mesmo ano, 1907, ele próprio pensou escrever «a kind of Sartor Resartus» [uma espécie de Sartor Resartus].O Livro do Desassossego, que contém duas referências à obra, é estruturalmente diversíssimo, mas espiritualmente próximo devido à herança ou coincidência de alguns temas e também à prosa inventiva que os exprime. Ambas as obras avançam sem avançar, atabalhoadamente e sem medo do caos (ZENITH, 2013, p.7).

Em estudo sobre a formação intelectual e artística de Pessoa na África do Sul, Alexandrino E. Severino dedicou um capítulo do seu livro a pesquisar a influência de Carlyle sobre o escritor português. O estudioso destaca que a seção $\mathrm{A}$ da prova de inglês do exame prestado na Durban High School correspondia à segunda parte do livro Past and Present, intitulado "The Ancient Monk", em que Carlyle analisa a vida social e política de uma comunidade religiosa do século XII comandada por um frade do Convento de St. Edmundsbury. Tendo por base a crônica de um dos frades, o Abade Joscelin de Brakenbold, o historiador vitoriano faz comparação entre essa sociedade e a Inglaterra urbana e industrial do século XIX. O Abade Samsom, eleito pela comunidade religiosa esclarecida, é contraposto à apatia dos chefes políticos locais. Para Severino (1983, p.255), Carlyle concebe as ações dos componentes da sociedade medieval de St. Edmundsbury como uma característica primordial do povo inglês, que seria a confiança que demonstra no poder de Deus. Para tal visão, os monges do convento, por reconhecer e acatar o postulado superior divino, ainda que permeados pela falta de religiosidade e fraqueza humana, regeneram-se aos olhos do ensaísta porque seriam homens confiantes. Em vista disso, recebem como prêmio a possibilidade de escolher o seu capelão-mor. Este, por sua vez, é um líder consciente da missão que lhe foi confiada superiormente, conduzindo seus representados com integridade, ainda que com mãos de ferro, transcendendo as leis da sociedade e as atribuições do monarca.

Superior à mão forte de um líder, estaria a força do poder divino, por meio do qual os acontecimentos seriam determinados. Em diversos trechos de sua obra, como evidencia Severino (1983, p.256-257), Carlyle vislumbra um líder semelhante para a sua época: “O ye kind Heavens, 
there is in every Nation and Community a fittest, a wisest, bravest, best; whow we could find and make King over us, all were in very truth; the best that God and Nature had permitted us to make it" (CARLYLE apud SEVERINO, 1983, p.256-257). A realização de uma forma ideal de governo baseada na aristocracia do talento a partir de um líder iluminado é antevista pelo autor para um futuro próximo: "How much is still alive in England; how much has not yet come to life. [...] The Centuries are big: and the birth hour is coming, not yet come. Tempus ferax, tempus edax rerum" (CARLYLE apud SEVERINO, 1983, p.256-257).

Este trecho partilha do mesmo tom de vaticínio de Mensagem, apontando para o surgimento de um tempo de redenção, no qual o espírito de decadência dará espaço a uma nova configuração das relações humanas, em que os valores serão muito mais espiritualizados e regidos pela ascendência divina. Tempo em que cada nação saberá o seu papel no palco das relações internacionais e será movida por um objetivo comum, que é, para esta concepção carlyleana, uma espécie de harmônica integração entre a natureza humana e divina, tal qual a epígrafe de natureza utópica inscrita em Mensagem, "Pax in Excelsis". A frase latina a que Carlyle faz referência, "Tempus ferax, tempus edax rerum”, encontra-se ipsis litteris nas Metamorfoses de Ovídio [Livro XC, verso 234] que, numa tradução possível, seria "tempo fecundo; tempo devorador das coisas", indicando a inexorabilidade da mudança e o surgimento de uma nova ordem humana.

Pessoa e Carlyle apostam na escatologia da expectação messiânica, cujas raízes estão nas narrativas judaico-cristãs. Em 1934, é publicado um texto intitulado "Portugal Vasto Império" (resposta a um inquérito publicado em 1926 no Jornal do Comércio e das Colônias), no qual Pessoa afirma que Portugal é "por índole, uma nação criadora e imperial", acrescenta que a partir do sonho sebastianista, "a ideia do Império Português atinge o estado religioso", o que levará ao surgimento do Quinto-Império (PESSOA, 1979, p.100). Ressalta que esse Império não será político: "Para o destino que presumo que será o de Portugal, as colônias não são precisas". Pessoa identifica ainda a necessidade de construir, renovar e difundir um grande mito nacional. Está, pois, referindo-se ao mito sebastianista.

Temos, felizmente, o mito sebastianista, com raízes profundas no passado e na alma portuguesa. Nosso trabalho é pois mais fácil; não temos que criar um mito, senão que renová-lo. Comecemos por nos embebedar desse sonho, por o integrar em nós, por o encarnar. Feito isso, cada um de nós independentemente e a sós consigo, o sonho se derramará sem esforço em tudo que dissermos ou escrevermos, e a atmosfera estará criada, em que todos os outros, como nós, o respirem. Então se dará na alma da Nação o fenómeno imprevisível de onde nascerão as Novas Descobertas, a Criação do Mundo Novo, o Quinto Império. Terá regressado El-Rei D. Sebastião (PESSOA, 1979, p.100). 


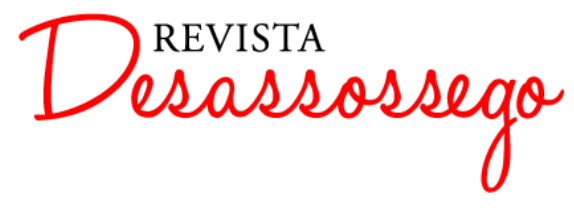

DESASSOSSEGO 12 | DEZ/2014 | ISSN 2175-3180

DOI: http://dx.doi.org/10.11606/issn.2175-3180.v6i12p33-45

Carlyle não tem à disposição um mito de alto teor simbólico e representativo do caráter nacional como o sebastianismo. Porém, narra, em Past and Present, sobretudo pela influência do romantismo alemão, uma história de um herói anônimo ocorrida num mosteiro da Idade Média, que revelaria a tenacidade e a capacidade de organização do espírito inglês numa sociedade hierarquizada, pela qual Carlyle idilicamente anseia. Tal prerrogativa foi notada por Pessoa no seu ensaio da época de escola como um expediente do autor para fixar a representação do sentimento nacional, evidenciando que o progresso social e político caminha em comunhão com a literatura. O contexto de produção carlyleana se deve, como identificou Raymond Williams (1969, p.91), às leituras de Goethe, Schiller, Jean Paul e Novalis. Carlyle atribuía aos românticos a possibilidade de uma conversão que lhe permitisse estar livre do sentimento de descrença do pensamento iluminista. O ensaísta acreditava que a sua obra não só deveria lhe possibilitar o sustento material, mas também prazer intelectual e elevação espiritual que apresentasse à sociedade um projeto de reconstrução a partir de bases não-materiais. E é justamente por meio dessas bases míticoespirituais que podemos estabelecer o diálogo com Pessoa, para quem o mito é a maneira mais segura de promover a ação sobre o mundo. A interpretação sob a ótica pessoana do sebastianismo, para além de evidenciar a consciência da identidade nacional, tal como propunha Carlyle, postula um novo sentido simbólico para o Encoberto, no qual se distancia do sentido literal da vinda do rei-Messias, para o surgimento de uma figura, um guia, um gênio que seria “prenúncio do estado futuro da humanidade". Esse é um expediente crítico que o poeta lança em seus artigos publicados na revista A Agnia, em 1912, sobre A Nova Poesia Portuguesa, sobretudo na correlação de forças entre períodos de desenvolvimento e decadência social, aliados à qualitativa produção literária.

Pessoa dá um passo adiante na discussão apresentada por Carlyle porque pressupõe o advento de um supra-Camões, que seria uma síntese e soma dos ideais do herói como homem de letras e da realização de um Quinto-Império. Chega-se então a uma característica que une Pessoa e Carlyle: a legitimação do papel do escritor. Segundo Bossche (1991, p.72), a figura do artista em Carlyle está relacionada a uma espécie de legislador ou rei, como voz dotada de autoridade teológico-política capaz de restabelecer antigos valores, como o da teocracia. Para Carlyle, a literatura seria uma substituta da religião.

This myth of poetic inspiration and genius represented poets as transhistorical individuals whose visionary capacity gives them the transcendental authority of both prophets and kings. Since literary men were prophets who would constitute the new church, their literary productions would be its liturgy and revealed texts, replacing the discourse of Christianity with literary discourse (BOSSCHE, 1991, p.30). 


\section{$A$ aristocracia do gênio}

Em Pessoa, o ethos do gênio configura-se como um discurso de autoridade, no qual se evidencia não só o desejo de legitimar o fazer literário, como se procura, dentro dos limites dessa narrativa, diferenciar entre aqueles escritores que fazem "arte meramente pela arte" e aqueles que têm "um dever a cumprir para com nós próprios e para com a humanidade" (PESSOA, 1999, p.139). O gênio se inclui nessa última acepção. Essa perspectiva substitui, em termos carlyleanos, o discurso religioso e partilha dos valores aristocráticos defendidos pelo ensaísta, porque se coaduna com a ideia defendida pelo poeta, de que "erguer alto o nome de Portugal" exigiria a condução de um líder iluminado, carismático e superior em termos éticos. Tal crença levou Pessoa a apoiar sucessivas ilusões no campo político português, como o apoio, ainda que pontual, ao ditador Pimenta de Castro, a esperança em Sidónio Pais e sua "República Nova", bem como ao general Carmona, em que diz confiar por ter este "a mais segura mão de timoneiro que há anos temos tido" e por ter "mantido uma atitude que é rara em qualquer caso, e raríssima em política - a maleabilidade dentro da dignidade. É um aristocrata da adaptação” (PESSOA, 1993, p.217). Porém, o apoio do político à ditadura de Salazar fez com que o poeta deixasse de admirálo. Se Pessoa faz comentários elogiosos a políticos portugueses, chegando a postular a chegada de um presidente-Rei, é preciso reconhecer que a sua ideia de política transcende os partidos e ideologias e serve como metáfora para a sua defesa de uma hierarquia do mérito fundamentada numa aristocracia da cultura. O que o poeta reivindica é que se saia de uma "oligarquia das bestas" (denominação dada ao governo republicano de Afonso Costa) para uma "oligarquia dos melhores" (PESSOA, 1980, p.80). Em nota biográfica de 30 de março de 1935, Pessoa expõe a sua ideologia política:

Considera que o sistema monárquico seria o mais próprio para uma nação organicamente imperial como é Portugal. Considera, ao mesmo tempo, a Monarquia completamente inviável em Portugal. Por isso, a haver um plebiscito entre regimes, votaria, embora com pena, pela República. Conservador do estilo inglês, isto é, liberdade dentro do conservantismo, e absolutamente anti-reaccionário (PESSOA, 2003, p.203-206).

Trata-se evidentemente de um posicionamento político paradoxal, cujo objetivo é a defesa da convivência de posições antagônicas, uma espécie de síntese do pensamento monárquico e republicano. Em um fragmento sobre o projeto de uma Teoria da República Aristocrática, Pessoa faz críticas à democracia por ela não ser um regime de representação efetiva, pois "não pode haver democracia, porque o mero fato de haver sociedade inclui o fato 
aristocrático" (PESSOA, 2003, p.82). E em outro trecho: "O que a vida moderna tem conseguido é apenas disfarçar e hipocrisar [sic] a operação desse fato, do fato aristocrático. Num país onde haja o sufrágio universal domina o povo? Não domina. Dominam os partidos. Dominam minorias. Isto é — o fato aristocrático persiste, disfarçado e hipócrita” (PESSOA, 2003, p.82).

Carlyle também tece críticas ao processo eleitoral democrático, sobretudo pela esterilidade dos arranjos políticos que assolavam a Inglaterra em 1832, ano em que se discutia no parlamento a reforma política (Reform Bill): "Todos os homens de alguma visão podem perceber que não há finalidade na democracia; que nada se alcançaria com sua mais completa vitória exceto o vazio e a livre oportunidade de vencer" (CARLYLE apud WILLIAMS, 1969, p.98). O escritor argentino Jorge Luis Borges, em curso de literatura inglesa na Universidade de Buenos Aires, faz menção à natureza ditatorial do ensaísta:

Carlyle llega a condenar a la democracia. Por eso Carlyle, a lo largo de toda su obra, admira a los dictadores, a los que llamó strong men, "hombres fuertes". La frase ha perdurado todavía. Por eso escribió el elogio de Guillermo el Conquistador, escribió en tres volúmenes el elogio del dictador Cromwell, alabó al doctor Francia, alabó a Napoleón, alabó a Federico el Grande de Prusia. Y dijo en cuanto a la democracia que no era otra cosa sino "la desesperación de encontrar hombres fuertes", y que solamente los hombres fuertes podrían salvar la sociedad. (BORGES, sd, p.225)

O pensamento paradoxal do ensaísta reside, por um lado, na possibilidade de, em Past and Present, defender os trabalhadores ao entoar um louvor à "nobreza" do trabalho, elevando os operários da indústria à condição de cavalheiros (chilvary of labour) dos novos tempos: "Acordem, vocês, nobres trabalhadores, guerreiros da luta verdadeira: tudo isso precisa ser consertado. São vocês que já estão meio-vivos quem eu saúdo a ingressar na vida, quem eu conclamo, em nome de Deus, a sacudir longe seu sono enfeitiçado e a viver plenamente" (CARLYLE apud ARTHMAR, 2005, p.353). Por outro lado, e aqui se aproxima do pensamento pessoano, Carlyle defende uma aristocracia na qual se postula uma "oligarquia dos melhores". A sociedade ideal, para o ensaísta, seria governada por uma aristocracia de sábios, que desempenhariam sua liderança de maneira generosa, ainda que com mãos de ferro, aos quais os homens comuns deveriam reverenciar e obedecer cegamente. Segundo Arthmar (2005, p.353): "Carlyle mostra-se francamente favorável a esse arranjo social de inspiração teocrática, único com potencial, segundo ele, de conciliar a verdadeira liberdade espiritual interior com o imperativo de disciplina e dedicação fiel ao trabalho".

No campo político, as posições de Carlyle se assemelham às de Pessoa por sua coincidentia oppositorum, por sua crítica conservadora e anti-reacionária. Os ensaios carlyleanos de 
natureza política possuem uma dicção profética cujo foco de análise está no presente social da Inglaterra vitoriana, mas também se trata de um vaticínio acerca do futuro. Num artigo de 12/9/1928, publicado no jornal Notícias Ilustrado, Pessoa caracteriza as condições que determinam o fenômeno aristocrático: a hereditariedade, a inteligência aliada ao senso moral, bem como a força de vontade e a sorte (PESSOA, 1980, p.70). Pessoa estabelece, tal qual Carlyle, uma diferença entre o "trabalhador braçal" e "o homem de gênio":

Aceito um homem do povo como um irmão em Deus, como um irmão em Cristo mas não como irmão em Natureza. Perante a religião somos iguais; perante a Natureza e a ciência não há entre nós espécie alguma de igualdade. Onde quer que se estabeleça igualdade entre coisas naturalmente diferentes, há mística, há religião; o que não há é ciência (PESSOA, 1980, p.70).

Pessoa se auto-inclui na categoria dos homens de gênio, comparando-os aos iniciados de uma religião: "Ora a cultura é uma iniciação. E é-o porque tem a essência da iniciação — ser uma outra vida". Nestes termos, ele defende a aristocracia porque se opõe ao caráter reacionário e popular da democracia:

O ódio à ciência, as leis naturais, é o que caracteriza a mentalidade popular. O milagre é o que o povo quer, é o que o povo compreende. Que o faça Nossa Senhora de Lourdes ou de Fátima, ou que o faça Lenin nisso só está a diferença. O povo é fundamentalmente, radicalmente, irremediavelmente reacionário. $\mathrm{O}$ liberalismo é um conceito aristocrático, e portanto inteiramente oposto à democracia (PESSOA, 1980, p.52).

A noção pessoana de aristocracia é desenvolvida à luz da atenção a ela conferida por Carlyle, com sua sensível transposição do universo político ao cultural. Bossche identifica em Carlyle a defesa do ideal de aristocracia como uma busca de autoridade, uma espécie de refúgio contra o sentimento de descrença da sociedade europeia. Por ser fiel ao seu espírito de historiador e pensador social, Carlyle não abandonou o interesse por refletir sobre a autoridade do mito "autor" na Literatura, porém passou a se interessar cada vez mais pela autoridade em termos políticos: "In shifting from novel to history, from the question of individual faith to the problem of social belief, he had steadily become more interested in problems of polity rather than of literature" (BOSSCHE, 1991, p.106).

Enquanto, para Carlyle, a discussão sobre a autoridade está a serviço da revalorização da crença social nas instituições e nos homens públicos ingleses, cuja reflexão está intimamente relacionada ao contexto político da Inglaterra, em Pessoa, a busca por autoridade, ainda que tenha tido seus momentos de flerte com o cenário político local, representa um compromisso de 
ordem cultural, como uma defesa da instância autor que é ao mesmo tempo nacional e cosmopolita. Vale destacar a distinção que Pessoa faz entre o conceito de Estado e Nação. "A Nação é uma entidade natural, com raízes no passado, e, poder-se-ia acrescentar, em linguagem paradoxal mas justa, com raízes também no futuro" (PESSOA, 1979, p.118). O Estado seria, para o poeta, "fenômeno puramente do presente, tanto que se projeta em, e se consubstancia com, o Governo que esteja, de momento, de posse da atividade desse Estado. De posse da Nação ninguém pode estar, pois não há redes, ministeriais ou outras, com as quais se pesque o impalpável" (PESSOA, 1979, p.118). Pessoa faz a defesa do gênio relacionando-o à Nação e sua ideia de fecunda perenidade por oposição ao Estado, que seria regido por governos de turno de natureza finita.

Apareceram recentemente à superfície da terra social uns animais chamados directrizes. Definindo mal e depressa, esta palavra quer dizer que qualquer de nós tem que pensar pela cabeça de outra pessoa.

Tal intimação ou imposição não pode fazê-la ou pretender fazê-la senão o Estado ou quem nele manda, pois a Nação não se exprime através do Estado mas através dos indivíduos, e mormente através dos homens de génio, que são a concentração individual das forças íntimas da Nação. Ora os homens de génio não impõem directrizes: são-as.(PESSOA, 1979, p.118)

Aqui são lançadas as bases para uma poética do gênio que concebe os escritores como heróis nacionais, como instâncias míticas que espelhariam o sentimento da nação. Pessoa faz referência à noção de força ao definir "os homens de gênio" como "concentração individual das forças íntimas da Nação". Não se trata apenas de uma representação difusa do ser nacional, mas de uma individualização e transmutação de valores coletivos. Trata-se de um duplo movimento que congrega a representação do sentimento nacional, como também uma interpretação individual acerca do fenômeno. Tem-se como exemplo Mensagem, que é uma tentativa de interpretação sobre Portugal a partir da ascensão, apogeu e declínio da nação. Carlyle forneceu a Pessoa, na obra Past and Present, o modelo de um país feudal habitado por grandes homens que eram reverenciados por sua liderança nata. Esta visão seria um exemplo de construção salvífica para se pensar o futuro do heroísmo em tempos de decadência social e política. Essa era uma questão central para o poeta desde a profecia do supra-Camões, na qual associa seu surgimento ao período de crise nacional, pois se vivia em Portugal ainda sob o impacto indireto do episódio conhecido como Ultimatum, de 11 de janeiro de 1890, no qual o país sofrera uma de suas maiores humilhações pela Inglaterra. Este fato trouxe consequências funestas não só para a autoimagem da "alma" portuguesa, como representou o fim da monarquia, com o acirramento da luta entre 
monarquistas e republicanos. Chega-se então a uma noção essencial para a reconstituição das relações entre Pessoa e Carlyle, notadamente a discussão sobre o culto aos heróis.

No centro das contribuições de Carlyle para o pensamento pessoano está a supressão de fronteiras tanto temporais quanto espaciais como forma de compreender a representação do sentimento nacional. Exemplos desse modo de pensar são recorrentes na obra do escritor escocês. Ao escrever, por exemplo, sobre a comunidade dos monges da Idade Média inglesa, Carlyle antevê as origens não só da unidade da crença num Deus providencial como demonstra apostar nos valores que formariam a nação, ainda que tal experiência esteja circunscrita a uma pequena comunidade religiosa. Em torno das reflexões sobre o herói, Carlyle identifica Shakespeare como o herói nacional que todos os ingleses deveriam celebrar:

A América está separada de nós, tanto quanto um parlamento a pode separar. Não digais que isto é fantástico, porque há nisto muita realidade; temos um rei inglês que nem o tempo, nem o acaso, nem o Parlamento, nem a combinação de Parlamento podem destronar: El rei-Shakespeare! [...] Podemos imaginá-lo como radiante sobre todas as nações inglesas, de aqui a mil anos. De Parramatta, de Nova Iorque, em qualquer paróquia, onde houver homens ingleses e mulheres inglesas, uns dirão aos outros: "Sim, Shakespeare é nosso; fomos nós que o produzimos, falamos e pensamos com ele e por ele; somos do mesmo sangue e da mesma raça que ele". O político mais sensato, ou mais dotado de senso comum, poderá muito bem, se lhe aprouver, pensar em tudo isto (CARLYLE, 2002, p.109- 110).

Essa representação de Shakespeare pairando supra-geograficamente sobre todas as nações de língua inglesa assemelha-se, evidentemente, à autoprofecia de um supra-Camões, mas também a esta, efetuada por Bernardo Soares, na qual se concebe, em sonhos, gênio sobre Detroit, Michigan e a praça de Lisboa:

Eu, porém, que na vida transitória não sou nada, posso gozar a visão do futuro a ler esta página, pois efetivamente a escrevo; posso orgulhar-me, como de um filho, da fama que terei, porque, ao menos, tenho com que a ter. E quando penso isto, erguendo-me da mesa, é com uma íntima majestade que a minha estatura invisível se ergue acima de Detroit, Michigan e de toda a praça de Lisboa (PESSOA, 2013, p.165).

O pensamento aristocrático de Carlyle, sobretudo na obra Os Heróis, está relacionado a uma perspectiva menos política e mais cultural. Trata-se da instituição de uma aristocracia do gênio, em que os valores de dominação não estariam assentados na espada, mas na pena. Seria o mesmo expediente de Pessoa ao defender o imperialismo de poetas.

Por fim, ressalta-se a ideia de intervenção cultural. Ainda que essa prerrogativa se confunda com a dimensão política, enquanto projeção do nacional para além das fronteiras, tal 
concepção toma um caráter amplamente universalista porque o que Carlyle e Pessoa defendem é a primazia do heró́smo dos poetas como grupo heterogêneo e não coeso, mas irmanados em torno do sonho. Essa ausência de uma ação política efetiva está resumida de maneira contundente na "Estética da Abdicação":

Conformar-se é submeter-se e vencer é conformar-se, ser vencido. Por isso toda a vitória é uma grosseria. Os vencedores perdem sempre todas as qualidades de desalento com o presente que os levaram à luta que lhes deu a vitória. Ficam satisfeitos, e satisfeito só pode estar aquele que se conforma, que não tem a mentalidade do vencedor. Vence só quem nunca consegue. Só é forte quem desanima sempre. O melhor e o mais púrpura é abdicar. O império supremo é o do Imperador que abdica de toda a vida normal, dos outros homens, em quem o cuidado da supremacia não pesa como um fardo de jóias (PESSOA, 1966, p.63).

Abdicar da vida do homem comum é um atributo do gênio, e revela o alto grau do compromisso ético e estético com a obra de arte literária. Se no ideal da abdicação está de algum modo a impotência lúcida do homem do subsolo de Dostoiévski, é preciso reconhecer que é em Carlyle que este ideal se vislumbra como permanente assunção de valores imateriais. Trata-se de um império que se constrói em silêncio e que irmana Pessoa e Carlyle nas confluências do mito: "Honremos o grande império do silêncio, mais uma vez. Tesouro infinito esse, que não faz barulho nas nossas algibeiras, que não contamos por peça, que não exibimos diante dos homens! É talvez, de todas as coisas, a mais útil para cada um de nós, nestes tempos barulhentos" (CARLYLE, 2013, p.98).

\section{REFERÊNCIAS}

ARTHMAR, Rogério. "Ética calvinista, idealismo e revolução: Carlyle e a crítica da economia vitoriana". Estudos Econômicos. [online]. 2005, vol.35, n.2.

BORGES, Jorge Luiz. Borges Professor. Curso de literatura inglesa en la Universidade de Buenos Aires. Edição, investigação e notas Martóm Arias e Martín Hadis. Buenos Aires: Emecé Editores, sd. BOSSCHE, Chris R. Vanden. Carlyle and the search for authority. Columbus: Ohio State University Press, 1991.

CARLYLE, Thomas. Os Heróis. Apresentação e tradução de Álvaro Ribeiro. Lisboa: Guimarães Editores, 2002.

.Complete Work of Carlyle (Project Gutemberg). Sterling Edition. Disponível em: www.gutenberg.org/files/26159/26159-h/26159-h.htm. Acesso em: 23 de junho de 2014. MARTINS, Fernando Cabral. Dicionário de Fernando Pessoa e do Modernismo Português. Coordenação de Fernando Cabral Martins. São Paulo: Leyla, 2010.

MONTEIRO, Maria Encarnação. Incidências Inglesas na Poesia de Fernando Pessoa. Coimbra: 
Coimbra Editora, 1956.

PESSOA, Fernando. Mensagem. Organização, introdução e notas de Caio Gagliardi. São Paulo: Hedra, 2007.

.Páginas de Doutrina Estética. Organização, prefácio e notas de Jorge de Sena. Lisboa: Ed. Inquérito, 1946.

.Livro do Desassossego. Organização de Richard Zenith. São Paulo: Companhia das Letras, 2013.

Sobre Portugal - introdução ao problema nacional. Recolha de textos de Maria Isabel Rocheta e Maria Paula Morão. Introdução e organização de Joel Serrão. Lisboa: Ática, 1979.

.Novas Poesias Inéditas. Fernando Pessoa. Organização e notas de Maria do Rosário Marques Sabino e Adelaide Maria Monteiro Sereno. Lisboa: Ática, 1973.

.Correspondência 1905-1922. Organização, posfácio e notas de Manuela Parreira da Silva. Lisboa: Assirio e Alvim, 1999.

.Heróstrato e a Busca da Imortalidade. Organização, prefácio e notas de Richard

Zenith.Lisboa: Assírio \& Alvim,2000.

"A Nova Poesia Portuguesa". In: Textos de Crítica e de Intervenção. Lisboa: Ática, 1980.

.Escritos Autobiográficos, Automáticos e de Reflexão Pessoal, Edição de Richard Zenith, com a

colaboração de Manuela Parreira da Silva e tradução de Manuela Rocha. São Paulo: A Girafa Editora, 2006.

.Páginas Íntimas e de Auto-Interpretação. Fernando Pessoa. Textos estabelecidos e prefaciados por Georg Rudolf Lind e Jacinto do Prado Coelho. Lisboa: Ática, 1966.

.Pessoa Inédito. Fernando Pessoa. Orientação, coordenação e prefácio de Teresa Rita Lopes.

Lisboa: Livros Horizonte, 1993.

.Ultimatum e Páginas de Sociologia Política. Fernando Pessoa. Recolha de textos de Maria Isabel Rocheta e Maria Paula Morão. Introdução e organização de Joel Serrão. Lisboa: Ática, 1980.

SEVERINO, Alexandrino. E. Fernando Pessoa na Africa do Sul. Lisboa: Publicações Dom Quixote, 1983.

WILLIAMS, Raymond. "Thomas Carlyle”. Cultura e sociedade. 1780-1950. São Paulo: Editora Nacional, 1969.

ZENITH, Richard. "Livro do Desassossego: romance possível (var. impossível)". Comunicação apresentada no III Colóquio Internacional Fernando Pessoa.

http://www.congressointernacionalfernandopessoa.com/comunicacoes/richard_zenith.pdf Acesso em: 2 de maio de 2014. 